\title{
Association of intimate partner violence during pregnancy, prenatal depression, and adverse birth outcomes in Wuhan, China
}

\author{
Honghui Yu', Xueyan Jiang ${ }^{2}$, Wei Bao ${ }^{3}$, Guifeng $\mathrm{Xu}^{3,4}$, Rong Yang ${ }^{5}$ and Min Shen ${ }^{2 *}$
}

\begin{abstract}
Background: Intimate partner violence (IPV) among pregnant women constitutes a global public health problem and a potential risk factor for adverse maternal and fetal outcomes. The present study aimed to examine the associations among IPV during pregnancy, prenatal depression, and adverse birth outcomes in Wuhan, China.

Methods: A cross-sectional study was performed from April 2013 to March 2014 in Wuhan, China. Sociodemographic characteristics, IPV during pregnancy, and depressive symptoms during pregnancy were assessed in the third trimester of pregnancy. Birth outcomes were collected after delivery using medical records. Chi-square tests and logistic regression analysis were used to examine the association between IPV and prenatal depression, as well as the association between IPV combined with prenatal depression and adverse birth outcomes.

Results: After adjustment for covariates, there was a statistically significant association between IPV during pregnancy and prenatal depression (adjusted odds ratio [aOR] =2.50, 95\% confidence interval [CI]: 1.60-3.90). IPV during pregnancy $(\mathrm{aOR}=1.67,95 \% \mathrm{Cl}: 1.08-2.56)$ and prenatal depression $(\mathrm{aOR}=1.72,95 \% \mathrm{Cl}: 1.11-2.68)$ were significantly associated with adverse birth outcomes. Women experiencing psychological abuse had a significantly higher odds of prenatal depression $(\mathrm{aOR}=2.04,95 \% \mathrm{Cl}$ : 1.19-3.49) and of adverse birth outcomes $(\mathrm{aOR}=2.13,95 \%$ Cl: 1.08-2.58), compared with women who did not experience IPV and prenatal depression.

Conclusions: IPV during pregnancy and prenatal depression were significantly associated with adverse birth outcomes, after adjustment for socio-demographic and behavior factors. The findings suggest that early recognition of IPV and prenatal depression during antenatal care may protect pregnant women and improve birth outcomes.
\end{abstract}

Keywords: Intimate partner violence, Prenatal depression, Adverse birth outcome, Pregnancy

\section{Background}

Intimate partner violence (IPV) among pregnant women constitutes a global public health problem $[1,2]$ and is a potential risk factor for adverse maternal and fetal outcomes [3, 4]. IPV includes physical abuse, psychological abuse, sexual violence, and economic abuse in the home setting $[5,6]$. A study conducted by World Health Organization [7] based on household data from the Demographic and Health Surveys (DHS) and the International Violence Against Women Survey (IVAWS) across 19 countries showed that the prevalence of

\footnotetext{
* Correspondence: shenmin@hust.edu.cn

2Department of Maternal and Child Health, School of Public Health, Tongji Medical College, Huazhong University of Science and Technology, Wuhan 430030, China

Full list of author information is available at the end of the article
}

physical IPV during pregnancy was 3.8 13.5\% in Africa, 4.1 11.1\% in Americas, 1.8 6.6\% in Europe and 2.0$5.0 \%$ in Asia. Previous studies have suggested that IPV disproportionately affects low-income women, especially for pregnant women [8]. A previous survey showed that the prevalence of domestic violence among pregnant women was $15.9 \%$ in Japan [9], 6.5\% in the United States [10], 7.7\% in Spain [11], and 34.8\% in northern European countries [12]; however, the prevalence rates were much higher in less developed countries such as Iran (72.8\%) [13] and Nigeria (44.6\%) [14]. In China, the prevalence rates of IPV among pregnant women have been reported as 18.8\% in Hong Kong [15] and 11.3\% in Changsha [16].

(c) The Author(s). 2018 Open Access This article is distributed under the terms of the Creative Commons Attribution 4.0 International License (http://creativecommons.org/licenses/by/4.0/), which permits unrestricted use, distribution, and reproduction in any medium, provided you give appropriate credit to the original author(s) and the source, provide a link to the Creative Commons license, and indicate if changes were made. The Creative Commons Public Domain Dedication waiver (http://creativecommons.org/publicdomain/zero/1.0/) applies to the data made available in this article, unless otherwise stated. 
IPV during pregnancy does not only affect women's health; it also has adverse health effects for newborns and affects their development in childhood [17-19]. Previous studies have demonstrated a relationship between abuse during pregnancy and both low birth weight (LBW) and preterm birth (PTB) [13, 18-20]. Many studies have shown that pregnancy constitutes a particularly critical period because of women's increased vulnerability and body changes, increased economic pressure, and less frequent sexual relations [18, 21, 22]. Pregnant women experiencing IPV also experience depression and anxiety. Studies have shown that women experiencing abuse during pregnancy are 2.5 times more likely to report depressive symptomatology, compared with their non-abused counterparts [23, 24]. These symptoms may be the direct consequence trauma or the indirect consequence of domestic violence [25-27].

In China, little is known about the experience of IPV among pregnant women or about its impacts on mental health and on children. Therefore, this study aimed to investigate the association between IPV during pregnancy and prenatal depression and the associations of these variables with adverse birth outcomes, adjusting for covariates.

\section{Methods}

This study was carried out in Qiaokou District Maternal and Child Health Hospital, Dongxihu District People's Hospital, and Tongji Hospital from April 1, 2013, to March 31, 2014, in Wuhan, China. The participants were pregnant women attending prenatal examinations or delivery at the selected hospitals during the study period. All participants were assessed in the third trimester of pregnancy or prior to delivery. This study was approved by the Ethics Board of Tongji Medical College, Huazhong University of Science and Technology. Written informed consent was obtained from the participants.

The Abuse Assessment Screen (AAS) was used to assess IPV during pregnancy [28]. Women reporting yes on any of the IPV items for the period of the current pregnancy were defined having been exposed to IPV. The Chinese version of AAS was first used in 1999 by Leung to screen for IPV among Chinese women [28]. The Chinese AAS has demonstrated a satisfactory level of measurement accuracy, with high specificity $(\geq 89 \%)$ and positive predictive values $(\geq$ $80 \%)$ and satisfactory-to-high negative predictive values (66-93\%) [29]. IPV was defined as physical abuse, psychological abuse, sexual abuse, or economic abuse. Prenatal depression was measured using the Center for Epidemiologic Studies-Depression Scale (CES-D) [30]. The CES-D is a 20-item self-report scale designed to measure current levels of depressive symptoms and has been widely used in China. The
Cronbach's $\alpha$ of the CES-D overall has been shown to be 0.90 , and it is $0.68-0.86$ for each of the scale's factors [31]. CES-D scores range from 0 to 60 , with higher scores signifying more severe symptoms of depression. The participants were considered likely to be depressed if their scores were $\geq 20$.

Data were collected on the demographic characteristics of pregnant women and their partners, husbands' smoking and alcohol use behaviors, family status, and pregnancy-related complications. Information on birth outcomes and pregnancy-related complications was collected from medical records after delivery. Adverse birth outcomes included PTB, LBW, birth defects, asphyxia, and stillbirth. PTB was defined as birth prior to 37 weeks' gestation, following the definition of the World Health Organization [32]. Using the typical definition, stillbirth was defined as fetal death at or after 20 to 28 weeks of pregnancy [32]. LBW was defined using the World Health Organization's definition of an infant having a birth weight of $2499 \mathrm{~g}$ or less, regardless of gestational age. "Birth defect" is a phrase commonly used to describe congenital malformations (i.e., a congenital or physical anomaly that is recognizable at birth) [33]. Perinatal asphyxia is the medical condition resulting from a newborn infant being deprived of oxygen (hypoxia) for long enough to cause apparent harm. Miscarriage was defined as an early pregnancy loss, and live birth was defined as the baby being born alive, even if he/she died shortly afterward.

All statistical analyses were performed using SAS software, Version 9.4 (SAS Institute Inc., Cary, North Carolina). Descriptive statistics were used to calculate the prevalence of overall IPV and subtypes of IPV, including physical, psychological, and sexual abuse-categorical variables described by frequency distributions. Chi-square tests were used for bivariate analyses to assess differences in the prevalence rates of IPV. Continuity-adjusted chi-square analysis was applied when $25 \%$ of the cells had expected counts of less than five. Multivariable logistic regression was used to estimate the adjusted odds ratios (ORs) and 95\% confidence intervals (CIs) for differences between the abused group and the non-abused group. All statistical tests were two-sided, and significance was determined using an alpha level of 0.05 .

\section{Results}

A total of 900 pregnant women participated in the survey. Of these women, 797 returned questionnaires that were eligible for data analysis. The average maternal age was $27.4 \pm 4.2$ years. More than one-third of the participants had received a bachelor's degree or higher, and more than half had monthly household incomes of less than 6000 yuan (Table 1). 
Table 1 Characteristics of pregnant women participated in the survey in Wuhan, China

\begin{tabular}{|c|c|c|c|c|}
\hline Variables & IPV (\%) & No IPV (\%) & $x^{2}$ value & $P$ value \\
\hline \multicolumn{5}{|l|}{ Age (years) } \\
\hline $20-24$ & $43(20.00)$ & $172(80.00)$ & \multirow[t]{4}{*}{0.6547} & \multirow[t]{4}{*}{0.8838} \\
\hline $25-29$ & $62(17.42)$ & $294(82.58)$ & & \\
\hline $30-34$ & $33(18.44)$ & $146(81.56)$ & & \\
\hline $35+$ & $8(17.02)$ & $39(82.98)$ & & \\
\hline \multicolumn{5}{|l|}{ Maternal education level ${ }^{* *}$} \\
\hline Junior middle school or below & $30(24.59)$ & $92(75.41)$ & \multirow[t]{4}{*}{17.2640} & \multirow[t]{4}{*}{0.0006} \\
\hline High school & $52(25.49)$ & $152(74.51)$ & & \\
\hline Vocational degree & $25(13.66)$ & $158(86.34)$ & & \\
\hline Bachelor degree or above & $39(13.54)$ & $249(86.46)$ & & \\
\hline \multicolumn{5}{|l|}{ Maternal occupation } \\
\hline Employed & $70(14.68)$ & $407(85.32)$ & \multirow[t]{2}{*}{10.5410} & \multirow[t]{2}{*}{0.0012} \\
\hline Unemployed & $76(23.75)$ & $244(76.25)$ & & \\
\hline \multicolumn{5}{|l|}{ Education level of husband } \\
\hline Junior middle school or below & $31(27.68)$ & $81(72.32)$ & \multirow[t]{4}{*}{9.7016} & \multirow[t]{4}{*}{0.0213} \\
\hline High school & $39(19.50)$ & $161(80.5)$ & & \\
\hline Vocational degree & $30(17.65)$ & $140(82.35)$ & & \\
\hline Bachelor degree or above & $46(14.60)$ & $269(85.4)$ & & \\
\hline \multicolumn{5}{|l|}{ Occupation of husbands } \\
\hline Employed & $126(18.89)$ & $541(81.11)$ & & \\
\hline Unemployed & $20(15.38)$ & $110(84.62)$ & & \\
\hline \multicolumn{5}{|l|}{ Household income monthly (Yuan) } \\
\hline$>3000$ & $43(25.6)$ & $125(74.4)$ & \multirow[t]{4}{*}{0.8937} & \multirow[t]{4}{*}{0.3445} \\
\hline $3000-$ & $61(19.55)$ & $251(80.45)$ & & \\
\hline $6000-$ & $28(14.66)$ & $163(85.34)$ & & \\
\hline$\geq 10,000$ & $14(11.11)$ & $112(88.89)$ & & \\
\hline \multicolumn{5}{|l|}{ Abortion history ${ }^{* *}$} \\
\hline Yes & $66(23.9)$ & $210(76.1)$ & \multirow[t]{2}{*}{8.8310} & \multirow[t]{2}{*}{0.0030} \\
\hline No & $80(15.4)$ & $441(84.6)$ & & \\
\hline \multicolumn{5}{|l|}{ Parity $^{* *}$} \\
\hline 1 & $67(14.5)$ & $396(85.5)$ & \multirow[t]{3}{*}{11.9798} & \multirow[t]{3}{*}{0.0025} \\
\hline 2 & $44(21.9)$ & $157(78.1)$ & & \\
\hline$\geq 3$ & $35(26.3)$ & $98(73.7)$ & & \\
\hline \multicolumn{5}{|l|}{ Husband's smoking behavior } \\
\hline Yes & $80(19.4)$ & $332(80.6)$ & \multirow[t]{2}{*}{0.6882} & 0.4068 \\
\hline No & $66(17.1)$ & $319(82.9)$ & & \\
\hline Husband's drinking behavior & & & & \\
\hline Yes & $113(17.4)$ & $537(82.6)$ & 2.0550 & 0.1517 \\
\hline No & $33(22.4)$ & $114(77.6)$ & & \\
\hline Pregnancy related complications & & & & \\
\hline Yes & $31(19.38)$ & $129(80.62)$ & 0.1493 & 0.6992 \\
\hline No & 115 (18.05) & $522(81.95)$ & & \\
\hline Adverse birth outcomes & & & & \\
\hline Yes & $39(26.53)$ & $108(73.47)$ & 8.1744 & 0.0042 \\
\hline
\end{tabular}


Table 1 Characteristics of pregnant women participated in the survey in Wuhan, China (Continued)

\begin{tabular}{llll}
\hline Variables & IPV (\%) & No IPV (\%) & $X^{2}$ value \\
\hline No & $107(16.44)$ & $544(83.56)$ & $P$ value \\
Prenatal depression & & & \\
Yes & $43(32.58)$ & $89(67.42)$ & 21.4908 \\
No & $103(15.49)$ & $562(84.51)$ & $<.0001$ \\
Total & $146(18.32)$ & $651(81.68)$ & \\
\hline
\end{tabular}

A total of $146(18.32 \%)$ of the pregnant women reported that they had experienced IPV by their husbands during the pregnancy. The prevalence rates of psychological, physical, economic, and sexual abuse were $14.3 \%, 2.1 \%, 2.0 \%$, and $0.3 \%$, respectively. The overall prevalence rate of adverse birth outcomes was $18.44 \%$ (147/797). The prevalence rates of neonatal asphyxia, PTB, and LBW were $12.3 \%, 8.9 \%$, and $5.3 \%$, respectively. The women who had adverse birth outcomes had a higher rate of IPV during pregnancy than did women without adverse birth outcomes $(26.53 \%$ vs. $16.44 \%, P=$ $0.0044)$. The IPV group had a higher prevalence rate of depression than did the non-IPV group $(32.58 \%$ vs. $15.49 \%, P<0.001$ ) (Table 1).

Table 2 showed the differences of prevalence rates among IPV group and no IPV group. The results suggested that women experienced IPV had higher rates of prenatal depression than those no IPV $(P<0.0001)$. For subtype of IPV, women experienced psychological, psychological and physical abuse had significant higher prevalence rates of prenatal depression $(P<0.01)$.

In the multivariable logistic regression analysis, after adjusting for potential confounding factors, IPV was significantly associated with prenatal depression. Pregnant women who had experienced IPV were 2.50 times more likely to report prenatal depression $(\mathrm{OR}=2.50,95 \% \mathrm{CI}$ :
1.60-3.90). In terms of the type of IPV, psychological abuse $(\mathrm{OR}=2.04,95 \% \mathrm{CI}: 1.19-3.49)$, psychological and economic abuse $(\mathrm{OR}=6.16,95 \% \mathrm{CI}$ : $1.48-25.58)$, and psychological and physical abuse $(\mathrm{OR}=21.81,95 \% \mathrm{CI}$ : 5.23-91.04) were significantly associated with prenatal depression (Table 3).

After adjusting for confounding factors, both IPV and prenatal depression had a significant association with adverse birth outcomes; the adjusted ORs for these variables were $1.72(\mathrm{OR}=1.72,95 \% \mathrm{CI}: 1.11-2.68)$ and 1.67 $(\mathrm{OR}=1.67,95 \% \mathrm{CI}: 1.08-2.56)$, compared with women reporting no IPV and no prenatal depression, respectively (Table 4). Regarding IPV subtype, only psychological abuse had a significant association with adverse birth outcomes $(\mathrm{OR}=2.13,95 \% \mathrm{CI}$ : $1.08-2.58)$.

\section{Discussion}

In this study, the prevalence of IPV among pregnant women in Wuhan, China, was $18.32 \%$. We observed a significant and positive association between IPV and prenatal depression among pregnant women. Moreover, both maternal IPV and prenatal depression were associated with adverse birth outcomes. The prevalence rate was similar to a previous study's finding of an 18.8\% prevalence of IPV among pregnant women in Hong Kong [15]. The prevalence rate was higher than a

Table 2 The differences of prevalence rates of depression among the IPV or the type of IPV group compared to no IPV group

\begin{tabular}{|c|c|c|c|c|}
\hline IPV or subtype of IPV & Prenatal depression (\%) & No prenatal depression (\%) & $x^{2}$ value & $P$ value \\
\hline Overall IPV & & & 21.4908 & $<.0001$ \\
\hline No & 89 (13.67) & $562(86.33)$ & & \\
\hline Yes & $43(29.45)$ & $103(70.55)$ & & \\
\hline Psychological abuse & & & 7.7637 & 0.0053 \\
\hline No & $107(15.22)$ & $596(84.78)$ & & \\
\hline Yes & $25(26.60)$ & $69(73.40)$ & & \\
\hline Psychological + physical abuse & & & $17.1939^{a}$ & $<.0001$ \\
\hline No & $125(15.88)$ & $662(84.12)$ & & \\
\hline Yes & $7(70.00)$ & $3(30.00)$ & & \\
\hline Psychological+ economic abuse & & & $3.2836^{\mathrm{a}}$ & 0.0700 \\
\hline No & $128(16.24)$ & $660(83.76)$ & & \\
\hline Yes & $4(44.44)$ & $5(55.56)$ & & \\
\hline Total & $132(16.60)$ & $665(83.40)$ & & \\
\hline
\end{tabular}

${ }^{a}$ Continuity Adjusted Chi-Square was applied because $25 \%$ of the cells have expected counts less than 5 
Table 3 Association between domestic violence during pregnancy and prenatal depression

\begin{tabular}{|c|c|c|c|c|}
\hline \multirow[t]{2}{*}{ Variables } & \multicolumn{2}{|l|}{ Model $1^{*}$} & \multicolumn{2}{|l|}{ Model $2^{*}$} \\
\hline & OR $(95 \% \mathrm{Cl})$ & $P$ value & OR $(95 \% \mathrm{Cl})$ & $P$ value \\
\hline Overall IPV & $2.50(1.60,3.90)$ & $<.0001$ & - & - \\
\hline \multicolumn{5}{|l|}{ Subtypes } \\
\hline Psychological abuse & - & - & $2.04(1.19,3.49)$ & 0.0092 \\
\hline Psychological+ economic abuse & - & - & $6.16(1.48,25.58)$ & 0.0123 \\
\hline Psychological+ physical abuse & - & - & $21.81(5.23,91.04)$ & $<.0001$ \\
\hline
\end{tabular}

Model 1: Adjusted for maternal age, maternal education, maternal occupation, husbands' education, husbands' occupation, husbands' drinking and smoking characteristics, pregnancy related complications and abortion history, overall domestic violence as an independent factor;

Model 2: Adjusted for maternal age, maternal education, maternal occupation, husbands' education, husbands' occupation, husbands' drinking and smoking characteristics, pregnancy related complications and abortion history, subtypes of domestic violence as independent factors

previous finding of $11.3 \%$ for overall prevalence of IPV among women during pregnancy in Changsha city [16]. Psychological abuse (14.6\%) was the most common form of abuse, accounting for $64.38 \%$ of abuse experienced by the women in this study. This was followed by physical abuse $(2.1 \%)$. This finding was consistent with a previous study in China, which found that psychological violence was the most common form of violence among pregnant Chinese women $(59 / 96=61.5 \%)$ [16]. A previous study in Iran also found that psychological violence was the most common form of violence among pregnant women (51.3\%) [34]. A study in Thailand reported that 54\% of women had been exposed to emotional violence, $27 \%$ to physical violence, and $19 \%$ to sexual violence [35]. Further, a meta-analysis of 92 studies from 23 countries focusing on IPV among pregnant women reported the prevalence of domestic violence as $13.3 \%$ in developed countries, compared to $27.7 \%$ for developing countries $(P=0.14)[36]$.

We found that women who had experienced IPV during pregnancy had a higher prevalence of depressive symptoms than did those who had not experienced IPV (29.45\% vs. $13.67 \%, P<0.0001)$. After adjustment for women's and their husbands' demographic characteristics, smoking, and alcohol use, overall IPV was associated with an increased risk of prenatal depression $(\mathrm{OR}=2.50$, 95\% CI: 1.60-3.90). Additionally, psychological abuse was significantly associated with prenatal depression ( $\mathrm{OR}=2.04,95 \% \mathrm{CI}: 1.19-3.49)$, and psychological abuse combined with economic abuse increased the odds of developing prenatal depression by six times $(\mathrm{OR}=6.16,95 \% \mathrm{CI}: 1.48-25.58)$ compared to those no IPV and prenatal depression. Our findings confirmed that IPV could lead to maternal depression and to a variety of adverse pregnancy outcomes.

Previous work has found strong associations between IPV and adverse outcomes, including LBW and PTB among women $[37,38]$. In this study, we found that IPV during pregnancy was significantly associated with an increased odds of adverse birth outcomes (OR $=2.50,95 \%$ CI: 1.60-3.90). This finding was consistent with previous studies. In Iran, a significant association was found between IPV and preterm labor $(\mathrm{OR}=1.54$, 95\% CI: $1.16-$ 2.03) [13]. In Vietnam, exposure to IPV was found to be associated with an increased risk of PTB (OR $=13.3$, 95\% CI: 2.5-69.9) and an increased risk of LBW (OR = 9.4, 95\% CI: 2.0-44.3) among pregnant women [20]. Similar results were found in the United States, where IPV exposure was shown to increase the odds of the prematurity $(\mathrm{OR}=1.45,95 \% \mathrm{CI}: 1.29-1.62)$, LBW $(\mathrm{OR}=$ 1.57, 95\% CI: $1.25-1.97$ ), and respiratory problems (OR $=1.17,95 \%$ CI: 1.04-1.32) [4]. A recent study in India using adjusted regression models also revealed a significant association between IPV and both miscarriage (OR $=1.35,95 \% \mathrm{CI}: 1.11-1.65)$ and stillbirth $(\mathrm{OR}=1.36,95 \%$ CI: 1.02-1.82) [39].

We also found that women exposed to different types of IPV had different effects on prenatal depression and adverse birth outcome. Previous studies found that exposure to psychological and sexual violence may

Table 4 Association of domestic violence during pregnancy+ prenatal depression and adverse birth outcomes

\begin{tabular}{|c|c|c|c|c|}
\hline \multirow[t]{2}{*}{ Variables } & \multicolumn{2}{|l|}{ Model $1^{*}$} & \multicolumn{2}{|l|}{ Model 2* } \\
\hline & OR $(95 \% \mathrm{Cl})$ & $P$ & OR $(95 \% \mathrm{Cl})$ & $P$ \\
\hline Prenatal depression & $1.72(1.11,2.68)$ & 0.0161 & $1.76(1.13,2.73)$ & 0.0124 \\
\hline Domestic violence & $1.67(1.08,2.56)$ & 0.0202 & - & - \\
\hline Only psychological abuse & - & - & $2.13(1.08,2.58)$ & 0.0026 \\
\hline
\end{tabular}

Model 1: Adjusted for maternal age, maternal education, maternal occupation, husbands' education, husbands' occupation, husbands' drinking and smoking characteristics, pregnancy related complications and abortion history, prenatal depression and overall domestic violence as independent factors; Model 2: Adjusted for maternal age, maternal education, maternal occupation, husbands' education, husbands' occupation, husbands' drinking and smoking characteristics, pregnancy related complications and abortion history, prenatal depression and subtypes of domestic violence as independent factors 
influence the pregnancy through alterations in women's psychological wellbeing and lifestyle habits. Poor psychological wellbeing, in turn, may lead to hypertension or preeclampsia, which may be associated with insufficient weight gain and PTB $[40,41]$. We also found significant associations between psychological abuse and prenatal depression (OR $=2.04,95 \% \mathrm{CI}: 1.19-3.49)$ and between psychological abuse and adverse birth outcomes $(\mathrm{OR}=$ 2.13, 95\% CI: 1.08-2.58). In addition, women experiencing psychological abuse combined with subtype of physical IPV or economic IPV had higher odds ratios of adverse birth outcomes, compared with women who were not exposed to abuse. Taken together, our results show that IPV exposure, especially to psychological abuse, was significantly associated with prenatal depression and with adverse birth outcomes. These findings were consistent with a previously conducted prospective cohort study of IPV during pregnancy and adverse pregnancy outcomes in Vietnam [20].

The present study had several limitations. First, because the data on IPV and depression during pregnancy were collected in a cross-sectional study, we cannot establish the temporal relation between these two conditions. Second, we did not consider experiences of IPV or depressive symptoms prior to pregnancy that might be a potential factor of prenatal depression. The separate and combined associations of these conditions before and during pregnancy with birth outcomes warrant further investigation. Third, we should be careful to generalize the data to the completely pregnant population because the finding was obtained from a city of central China.

\section{Conclusions}

This study has shown that IPV and prenatal depression were common among pregnant women in Wuhan, China. IPV was significantly associated with prenatal depression, and both IPV and prenatal depressive symptoms were associated with risk increasing of adverse birth outcomes, which are deleterious to maternal and newborn outcomes. The findings suggested that screening for IPV and prenatal depressive symptoms during prenatal care is necessary and might be helpful in reducing adverse outcomes for both mothers and newborns.

\section{Abbreviations}

AAS: The Abuse Assessment Screen; ABO: Adverse birth outcomes; aOR: Adjusted odds ratio; CES-D: The Center for Epidemiologic StudiesDepression scale; Cl: Confidence interval; IPV: Intimate partner violence; LBW: Low birth weight; PTB: Preterm birth; WHO: World Health Organization

\section{Acknowledgments}

We are extremely grateful to all the mothers who took part in the study, to the nurses for their help in recruiting them. We thank Jennifer Barrett, PhD, from Liwen Bianji, Edanz Editing China (www.liwenbianji.cn/ac), for editing the English text of a draft of this manuscript.

\section{Funding}

The fund for this research was obtained from the Natural and Science Foundation of Hubei Province (2013CFB125). However, it had no role in the design of the study, collection, analysis, interpretation of data, and in writing the manuscript.

\section{Availability of data and materials}

The datasets analyzed in the current study are available from the corresponding author on reasonable request.

\section{Authors' contributions}

Conceived and designed the study: MS. Supervised and performed the survey, involved in participant recruitment and interpreted the analysis: $\mathrm{HHY}$ and RY. Involved in Collecting, managing and analysis of the data: XYJ. Drafted the manuscript, revised the paper upon reviewers' comments and wrote the final manuscript: HHY and MS. Critical review and thoroughly edited the manuscript: WB and GFX. WB and GFX also supported the suggestion and explanation on the data analysis of the manuscript. All authors read and approved the final manuscript.

\section{Ethics approval and consent to participate}

This study is conducted in accordance with the Declaration of Helsinki, and all procedures were approved by the Ethics Board of Tongji Medical College, Huazhong university of Science and Technology (ID 2012S311). All participants provided informed consent with an electronic signature.

Consent for publication

Not applicable.

\section{Competing interests}

The authors declare that they have no competing interests.

\section{Publisher's Note}

Springer Nature remains neutral with regard to jurisdictional claims in published maps and institutional affiliations.

\section{Author details}

${ }^{1}$ Department of Anesthesiology, Tongji Hospital affiliated Tongji Medical College, Huazhong University of Science and Technology, Wuhan 430030, China. ${ }^{2}$ Department of Maternal and Child Health, School of Public Health, Tongji Medical College, Huazhong University of Science and Technology, Wuhan 430030, China. ${ }^{3}$ Department of Epidemiology, College of Public Health, University of lowa, lowa City, IA 52242, USA. ${ }^{4}$ Center for Disabilities and Development, University of lowa Stead Family Children's Hospital, lowa City, IA 52242, USA. 'Wuhan Children's Hospital (Wuhan Maternal and Child Healthcare Hospital), Tongji Medical College, Huazhong University of Science \& Technology, Wuhan 430015, China.

Received: 1 December 2017 Accepted: 22 November 2018

Published online: 03 December 2018

\section{References}

1. Tjaden P. TNE: nature and consequences of intimate partner violence: findings from the National Violence against Women Survey. Washington, DC: Department of Justice; 2000.

2. Petersen R, Gazmararian JA, Spitz AM, Rowley DL, Goodwin MM, Saltzman LE, Marks JS. Violence and adverse pregnancy outcomes: a review of the literature and directions for future research. Am J Prev Med. 1997;13(5):366-73.

3. Shah PS, Shah J. Knowledge synthesis group on determinants of preterm LBWB: maternal exposure to domestic violence and pregnancy and birth outcomes: a systematic review and meta-analyses. J Women's Health (Larchmt). 2010;19(11):2017-31.

4. Pavey AR, Gorman GH, Kuehn D, Stokes TA, Hisle-Gorman E. Intimate partner violence increases adverse outcomes at birth and in early infancy. J Pediatr. 2014;165(5):1034-9.

5. Committee on Health Care for Underserved W. ACOG Committee opinion no. 518: intimate partner violence. Obstet Gynecol. 2012;119:412-7.

6. Hinkle SN, Laughon SK, Catov JM, Olsen J, Bech BH. First trimester coffee and tea intake and risk of gestational diabetes mellitus: a study within a national birth cohort. BJOG. 2015;122(3):420-8. 
7. Devries KM, Kishor S, Johnson H, Stockl H, Bacchus L, Garcia-Moreno C, Watts C. Intimate partner violence during pregnancy: analysis of prevalence data from 19 countries. Reprod Health Matters. 2010;18(36):158-70.

8. Alhusen JL, Bullock L, Sharps P, Schminkey D, Comstock E, Campbell J. Intimate partner violence during pregnancy and adverse neonatal outcomes in low-income women. J Women's Health (Larchmt). 2014; 23(11):920-6.

9. Kita S, Yaeko K, Porter SE. Prevalence and risk factors of intimate partner violence among pregnant women in Japan. Health Care Women Int. 2014; 35(4):442-57.

10. Beydoun HA, Tamim H, Lincoln AM, Dooley SD, Beydoun MA. Association of physical violence by an intimate partner around the time of pregnancy with inadequate gestational weight gain. Soc Sci Med. 2011;72(6):867-73.

11. Velasco C, Luna JD, Martin A, Caño A, Martin-de-las-Heras S. Intimate partner violence against Spanish pregnant women: application of two screening instruments to assess prevalence and associated factors. Acta Obstet Gynecol Scand. 2014;93(10):1050-8.

12. Lukasse M, Schroll AM, Ryding EL, Campbell J, Karro H, Kristjansdottir H, Laanpere M, Steingrimsdottir T, Tabor A, Temmerman M, et al. Prevalence of emotional, physical and sexual abuse among pregnant women in six European countries. Acta Obstet Gynecol Scand. 2014;93(7):669-77.

13. Hassan M, Kashanian M, Roohi M, Yousefi H. Maternal outcomes of intimate partner violence during pregnancy: study in Iran. Public Health. 2014;128(5): $410-5$.

14. Onoh R, Umeora O, Ezeonu P, Onyebuchi A, Lawani O, Agwu U. Prevalence, pattern and consequences of intimate partner violence during pregnancy at Abakaliki Southeast Nigeria. Ann Med Health Sci Res. 2014;3(4):484-91.

15. Chan KL, Brownridge DA, Tiwari A, Fong DY, Leung WC, Ho PC. Associating pregnancy with partner violence against Chinese women. J Int Viol. 2011;26(7): 1478-500.

16. Zhang Y, Zou S, Cao Y, Zhang Y. Relationship between domestic violence and postnatal depression among pregnant Chinese women. Int J Gynecol Obstet. 2012;116(1):26-30.

17. Jasinski JL. Pregnancy and domestic violence a review of the literature. Trauma Violence Abuse. 2004;5(1):47-64.

18. Alhusen JL, Bullock L, Sharps P, Schminkey D, Comstock E, Campbell J. Intimate partner violence during pregnancy and adverse neonatal outcomes in low-income women. J Women's Health. 2014;23(11):920-6.

19. Donovan BM, Spracklen CN, Schweizer ML, Ryckman KK, Saftlas AF. Intimate partner violence during pregnancy and the risk for adverse infant outcomes: a systematic review and meta-analysis. BJOG. 2016;123(8):1289-99.

20. Hoang TN, Van TN, Gammeltoft T, D WM, Nguyen Thi Thuy H, Rasch V. Association between intimate partner violence during pregnancy and adverse pregnancy outcomes in Vietnam: a prospective cohort study. PLoS One. 2016; 11(9):e0162844.

21. McFarlane J, Parker B, Soeken K, Bullock L. Assessing for abuse during pregnancy. Severity and frequency of injuries and associated entry into prenatal care. JAMA. 1992;267(23):3176-8.

22. Alhusen JL, Ray E, Sharps P, Bullock L. Intimate partner violence during pregnancy: maternal and neonatal outcomes. J Women's Health (Larchmt). 2015;24(1):100-6.

23. Connelly CD, Hazen AL, Baker-Ericzen MJ, Landsverk J, Horwitz SM. Is screening for depression in the perinatal period enough? The cooccurrence of depression, substance abuse, and intimate partner violence in culturally diverse pregnant women. J Women's Health (Larchmt). 2013; 22(10):844-52.

24. Witt WP, Wisk LE, Cheng ER, Hampton JM, Creswell PD, Hagen EW, Spear HA, Maddox T, Deleire T. Poor prepregnancy and antepartum mental health predicts postpartum mental health problems among US women: a nationally representative population-based study. Womens Health Issues. 2011;21(4):304-13.

25. Audi CA, Segall-Correa AM, Santiago SM, Andrade Mda G, PerezEscamila R. Violence against pregnant women: prevalence and associated factors. Rev Saude Publica. 2008;42(5):877-85.

26. Gazmararian JA, Lazorick S, Spitz AM, Ballard TJ, Saltzman LE, Marks JS. Prevalence of violence against pregnant women. JAMA. 1996;275(24): 1915-20.

27. Shamu S, Abrahams N, Temmerman M, Musekiwa A, Zarowsky C. A systematic review of African studies on intimate partner violence against pregnant women: prevalence and risk factors. PLoS One. 2011;6(3):e17591.
28. Leung $W$, Leung $T$, Lam $Y$, Ho P. The prevalence of domestic violence against pregnant women in a Chinesecommunity: social issues in reproductive health. Int J Gynecol Obstet. 1999;66(1):23-30.

29. Zhang Y, Zou S, Cao Y, Zhang Y. Correlation of domestic violence and postnatal depression among pregnant women. Chin J Clin Psychol. 2012; 20(4):506-9.

30. Radoff LS. The CES-D scale: a self-report depression scale for research in the general population. Appl Psychol Meas. 1977;1:385-401.

31. Zhang J, Wu Z, Fang G, et al. Development of the Chinese age norms of CES-D in urban area. Chin Ment Health J. 2010;24(2):139-43.

32. Lawn JE, Gravett MG, Nunes TM, Rubens CE, Stanton C, Group GR. Global report on preterm birth and stillbirth (1 of 7): definitions, description of the burden and opportunities to improve data. BMC Pregn Childbirth. 2010; 10(Suppl 1):S1.

33. World Health Organization Congenital anomalies. http://www.who.int/ mediacentre/. Accessed 20 Oct 2018

34. Jamshidimanesh M, Soleymani M, Ebrahimi E, Hosseini F. Domestic violence against pregnant women in Iran. J Family Reprod Health. 2013;7(1):7-10.

35. Saito A, Creedy D, Cooke M, Chaboyer W. Effect of intimate partner violence on antenatal functional health status of childbearing women in northeastern Thailand. Health Care Women Int. 2013;34(9):757-74.

36. James L, Brody D, Hamilton Z. Risk factors for domestic violence during pregnancy: a meta-analytic review. Violence Vict. 2013;28(3):359-80.

37. Grote NK, Bridge JA, Gavin AR, Melville JL, lyengar S, Katon WJ. A metaanalysis of depression during pregnancy and the risk of preterm birth, low birth weight, and intrauterine growth restriction. Arch Gen Psychiatry. 2010; 67(10):1012-24

38. Fonseca-Machado Mde O, Alves LC, Monteiro JC, Stefanello J, Nakano AM, Haas VJ, Gomes-Sponholz F. Depressive disorder in pregnant Latin women: does intimate partner violence matter? J Clin Nurs. 2015;24(9-10):1289-99.

39. Dhar D, McDougal L, Hay K, Atmavilas Y, Silverman J, Triplett D, Raj A. Associations between intimate partner violence and reproductive and maternal health outcomes in Bihar, India: a cross-sectional study. Reprod Health. 2018;15(1):109.

40. Zhang Y, Zou S, Zhang X, Zhang Y. Correlation of domestic violence during pregnancy with plasma amino-acid neurotransmitter, cortisol levels and catechol-o-methyltransferase Val(158)met polymorphism in neonates. Asia Pac Psychiatry. 2013;5(1):2-10.

41. Zhang Y, Zhang YL, Zou SH, Zhang XH, Cao YP, Yang SC. Correlation between domestic violence in pregnancy and the levels of plasma amino acids and cortisol in the neonates. Zhonghua Nei Ke Za Zhi. 2008;47(3):209-12.

Ready to submit your research? Choose BMC and benefit from:

- fast, convenient online submission

- thorough peer review by experienced researchers in your field

- rapid publication on acceptance

- support for research data, including large and complex data types

- gold Open Access which fosters wider collaboration and increased citations

- maximum visibility for your research: over $100 \mathrm{M}$ website views per year

At $\mathrm{BMC}$, research is always in progress.

Learn more biomedcentral.com/submissions 